\title{
The oxidation of bitumen witnessed in-situ by infrared spectroscopy
}

\author{
Michalina Makowska $₫$ - Ari Hartikainen - Terhi Pellinen
}

Received: 23 March 2017/ Accepted: 6 June 2017/Published online: 13 June 2017

(C) The Author(s) 2017. This article is an open access publication

\begin{abstract}
During the production and recycling of asphalt concrete, bitumen in contact with inorganic particles is exposed to air at high temperatures. As a result an oxidation of bitumen, also known as aging, occurs. The reaction between bitumen and air at $163{ }^{\circ} \mathrm{C}$ was studied insitu with and without the presence of inorganic impurities by means of fourier transform infrared spectroscopy in the attenuated reflectance mode. This oxidation was discovered to be a step-wise reaction facilitated by the oxidation of thiols and creation of peroxides within the system. The rate of reaction was demonstrated to depend on the type of impurity present, of which iron (III) chloride was the strongest catalyst. It was further demonstrated that the oxidation reaction is inhibited by the adsorption of thiol species present in the system on copper particles. Combining copper with the iron (III) chloride-containing system also resulted in the inhibition of signal increase in the sulfoxide region of the spectra. The results of this preliminary research on the bitumen oxidation reaction presented are proposed for further research regarding control of aging of asphalt concrete, especially during the recycling works.
\end{abstract}

Keywords Bitumen - Oxidation · FT-IR - ATR . Asphalt $\cdot$ Recycling

M. Makowska $(\bowtie) \cdot$ A. Hartikainen · T. Pellinen Department of Civil Engineering, Aalto University, Rakentajanaukio 4A, Espoo, Finland

e-mail: michalina.makowska@aalto.fi

\section{Introduction}

Bitumen is used as the adhesive agent in asphalt concrete (AC). Therefore, roads and highways constitute the largest single use of bitumen in the world [1]. Unfortunately, bitumen, a distillation product of crude oil, is a solution of organic molecules [2-4] which oxidize upon contact with air.

This material transformation has been correlated with the rheological changes [5-11], commonly referred to as stiffening of bitumen. The common explanation behind the bitumen oxidation reaction is that the uptake of oxygen into the bitumen results in increased polarity of the molecules, which is witnessed by the increasing signal in the carbonyl and sulfoxide characteristic regions in the infrared spectra [6]. The consensus is that the more there are polar components in the considered bitumen, the stiffer it is due to the increase of hydrogen bonding between the molecules [6].

From one perspective, the mild oxidation can be considered to be a positive change, as it improves the resistance to permanent deformation of AC. From the other, the high oxidation levels are associated with $\mathrm{AC}$ failures, such as raveling, block cracking, thermal cracking, moisture damage and potholes. Due to these aspects, the oxidation reaction observed in AC is often referred to as the aging of asphalt. Thus, the ability to prevent or even partially inhibit the oxidation of bitumen would be highly desirable and move us closer 
to a truly sustainable use of non-renewable natural resources.

Unfortunately, the phenomenon of bitumen oxidation is quite complex. Researchers are not dealing with a pure isolated molecule, but rather with thousands of species sharing a similar aromaticity or number of heteroatoms in their structure $[4,12]$, which can be divided into fractions based on their polarity. The most popular separation of bitumen molecules is known as Corbett fractionation, also known as SARA fractions, where starting from the least polar to the most polar species, we obtain saturates, naphthene aromatics, polar aromatics (a.k.a. resins) and asphaltenes [13]. The increase of the concentration of the asphaltenes during aging has been positively correlated with the increasing viscosity of bitumen [6].

It has been established that the interaction between bitumen and air over mineral aggregate surfaces [14] or inorganic salts [5] can affect the chemical composition of the product of such reaction.

The interaction of bitumen with air in the presence of catalysts was studied by Quddus et al. [5] in the context of the air blowing of the bitumen. The authors observed that iron chloride $\left(\mathrm{FeCl}_{3}\right)$ expressed significantly higher catalytic activity than other metal chlorides (zinc, cobalt, tin, chromium, and copper) at levels of $0.3 \%$ wt. During the air blowing of bitumen, the authors obtained a conversion from $12 \%$ asphaltenes in the feed bitumen, to $24 \%$ in blank, $34 \%$ using $0.3 \%$ wt of $\mathrm{FeCl}_{3}$, and $53 \%$ using $0.6 \%$ wt of $\mathrm{FeCl}_{3}$.

Interestingly, reports on multiply recycled asphalt pavements (RAP) in cold regions describe cases of excessive premature pavement failures [15]. The general fraction analysis of bitumens extracted from some of the field collected samples indicated almost $95 \%$ of cumulative content of asphaltenes and resins - the value indicating excessive aging, which was surprising and similar only to the values recorded for natural asphalts [16]. This pavement was proven to contain a material high in iron [17], not consistent with the original mix design, and a hypothesis was proposed that catalytic interaction occurred between bitumen and fines during recycling process.

The presence of $\mathrm{FeCl}_{3}$ in an asphalt mixture prepared from a virgin aggregate is on a very low level. However, even though bitumen is considered a waterproof material, the moisture penetrates into the AC through the capillary suction through mastic and aggregate [18] and so do de-icing liquids [19].
The chemical composition of the asphalt mixture changes over time in service, due to exposure to sodium and calcium chloride brines, typically used as de-icing chemicals in cold regions. It has been observed by the authors that the content of the chlorides in RAP correlates with the content of the iron in aggregate fines recovered from the field collected samples. Observations were made from RAP of the wearing course mixtures of various ages, compositions, and service history in the cold climate environment. In the worst case scenario, concentration of iron chloride was $0.55 \%$ wt of bitumen, a level similar to those established to facilitate strong catalytic oxidation in laboratory [5]. Unlike in conditions during in plant air blowing, the $\mathrm{FeCl}_{3}$ is expected to be present in hydrated form. The hydrated $\mathrm{FeCl}_{3}$ was reported to express different catalytic activity to that of dried version in some reactions [20].

The aging during the recycling of both aged and fresh bitumen in the context of recycling of RAP exposed to de-icers during the lifetime was interesting to study. In the hot mix asphalt, we would reheat the already aged bitumen, which remains in contact with aged aggregate, before it is mixed with the fresh AC and rejuvenating agents. In fact both aged and fresh bitumen remain in contact with aged fines at elevated temperatures.

Therefore, the fourier transform infrared spectroscope equipped with the Attenuated Total Reflectance accessory, and armed with a heat controlling unit, was used to conduct a time-resolved analysis of the bitumen oxidation reaction.

The aim of this research was to follow the oxidation reactions insitu during the first $60 \mathrm{~min}$ at $163{ }^{\circ} \mathrm{C}$ (conditions similar to those in the Rolling Thin Film Oven Test [21]) and to identify the changes in:

- bitumen upon contact with air;

- bitumen upon contact in air when in heterogeneous system with inorganic particles of which;

- calcium chloride $\left(\mathrm{CaCl}_{2}\right)$ was to represent a deicing chemical;

- hydrated iron (III) chloride $\left(\mathrm{FeCl}_{3} * \mathrm{H}_{2} \mathrm{O}\right)$ was to represent the product of reaction between de-icing chemicals and iron oxides in AC fillers which could be found in the recycled $\mathrm{AC}$; 
- hydrated lime $\left(\mathrm{Ca}(\mathrm{OH})_{2}\right)$ was to represent a filler reported previously as inhibitor of AC aging;

- the copper powder $(\mathrm{Cu})$ was to represent hereby found inhibitor of aging.

\subsection{Background}

In terms of studying the changes within the material the use of the transmission technique in the infrared analysis has been a preferred technique when following the oxidation reaction. Interestingly, the Attenuated Total Reflectance (ATR) mode of Fourier Transform Infrared spectroscopy (FT-IR) was already demonstrated to be an advantageous technique for studying the chemical composition of bitumen by Jemison et al. [22] in 1992. The sample in ATR can be applied as a bitumen droplet without any pre- or further processing, e.g. eliminating the effect of residual solvent in the film. Such a droplet can be casted into the mold of certain dimensions exceeding the depth of light wave penetration into the material. The control of the material thickness can be obtained by keeping it inside the holder during the measurements [23].

Nevertheless, the majority of the studies conducted in connection with the aging of bitumen involve an aging procedure outside of the FT-IR set-up (exsitu). Unfortunately, the exsitu measurements involve analytical risks. The aging of bitumen in contact with aggregates, as in the case of the actual field-aged samples, may lead to a transfer of silica dust into the bitumen during the extraction of bitumen from asphalt [24]. Similar problems occur in the contact with the catalysts, whose spectrum overlaps with the spectrum of bitumen, or in the case of material aging on the columns filled with clays or silica [14]. Additionally, such effects as the presence of residual solvent from extraction, aging of bitumen in the solutions or aging during drying of the casted samples, all add to the entanglement of the obtained final signal. Furthermore, the observation was made previously [25] that upon the extraction of bitumen from contact with fines, an actual transfer occurs of bitumen molecules into the aggregate. This was confirmed later on to be a function of solvent type, time of contact and stiffness of asphalt [26] where the additional conclusion was reached that it is almost impossible to remove all solvent used during extraction. Therefore, monitoring the reaction exsitu does not provide us with realistic information about all of the products of the oxidation reaction. Even in the works of Jemison et al. [22], where for the first time, FT-IR-ATR was used to characterize the aging of bitumen, the specimens were aged separately by employing the Rolling Thin Film Oven method [21]. To the best of our knowledge, in that process, the complete transfer of all the material out of the containers is troublesome, if not impossible. Additionally, during the test the evaporation of socalled volatile organic compounds (VOC) is observed, but not studied [21].

In contrast, recently developed tools allow for the study of the reactions insitu by FT-IR either in transmission mode or equipped with ATR [27, 28]. It does not eliminate the problem associated with change of concentration due to evaporation of VOC during aging, but allows us to follow the reaction at much shorter intervals without the necessity for sampling and specimen preparation. Incidentally, Karlsson et al. [23] have once used time-resolved insitu FT-IR by using ATR for the studies of diffusivity of molecules into the bitumen at different temperatures, where by using the fixed dimensions of the casted bitumen samples, the authors were able to determine the changes within the certain volume of sample with time.

In ATR the depth of penetration $\left(d_{\mathrm{p}}\right)$ of wave into the material is defined by equation:

$d_{\mathrm{p}}=\frac{\lambda}{2 \pi\left(\sin ^{2} \theta-n_{21}^{2}\right)^{1 / 2}}$

where $\lambda$ is the wavelength of incident light, $\theta$ is the angle of incidence of light, $n_{21}$ is the refractive index ratio between sample and the prism [29]. Unfortunately, the change in refractive index with the progress of the reaction is most likely occurring, which may affect to the Absorbance values. However, for the sake of simplification at this stage in our research it is assumed as constant.

The ray of light penetrates only to a certain depth in the material and the signal reflected is recorded [29]. The resulting spectra are an average of the sample properties for the certain distance between the prism and a fixed depth in the material tested. This method was thought to be helpful in following the oxidation kinetics in-situ.

According to the Beer-Lambert law, the Absorbance (A) of the material is proportional to the 
concentration of the absorbing species in the material according to the equation

$A=\varepsilon c l$,

where the proportionality constant $(\varepsilon)$ is called molar absorption coefficient $\left(\mathrm{dm}^{3} * \mathrm{~mol}^{-1} * \mathrm{~cm}^{-1}\right), c$ is concentration $\left(\mathrm{mol} * \mathrm{dm}^{-3}\right)$ and 1 is absorption path length $(\mathrm{cm})$ [30].

Therefore, for samples which assure the thickness of layer is greater than the depth of penetration of the wave into the material and in cases where $\varepsilon$ is not changing, while introducing constant

$b=1 / \varepsilon l$,

the rate of reaction can be represented by equation:

$r=\frac{\mathrm{dc}}{\mathrm{d} t}=\frac{\mathrm{d}(\mathrm{bA})}{\mathrm{d} t}$

However, the $\varepsilon$ can change during the reaction and this should be considered.

One of the complications comes from the nonlinearity of Eq. 2 in the whole range of concentrations in a mixture of changing medium. Additionally, during the oxidation we create both sulfoxide containing species (SO) and carbonyl containing ones (CO), and their Absorbance band overlaps within the SO region. Thus quantifying exactly the change of concentration of $\mathbf{S O}$ in bitumen, requires more advanced separation techniques [24]. Another issue is connected with steric position of those functional groups within one molecule, which may affect to the relative intensity of absorbance recorded for both regions [6, 30, 31]. An additional limitation of this technique lays in the insensitivity to e.g. polycondensated aromatic compounds [11].

Additionally, as bitumen is a mixture of molecules of various molecular size and shape, the description of the kinetics based on following a peak characteristic of a certain molecule becomes quite complicated as the position of the maximum of the characteristic peaks can shift during the aging of the material [6]. Because

$A=2-\log _{10} \% T$,

where Transmittance $[T]$ is

$T=I / I_{0}$,

and $I$ is intensity of beam passing through the sample, while $I_{0}$ is the intensity of the beam passing through reference, the step differential graphs are in fact a form of the graphical representations of change in intensity over change of time at all frequencies simultaneously (spectrograms).

In our opinion, the change in Absorbance over time could be used as a surrogate for rate of reaction sufficient for comparison between tested specimens and as such a surrogate it is being understood in this article. These types of spectrograms allow us to see that the considered reactions happen in steps and to trace the change in the rate of each of the simultaneous reactions at a fast glance. Additionally, we are able to observe signals of the formed side products when the focus is removed from only a few marker peaks.

All of the above is why we are wary to use molar concentration as a kinetic parameter. We are also aware that even though in this article we will talk about the lower rate of formation of a signal in carbonyl region in some combinations, this may in fact be lower rate of increase in absorbance-which is coming from all of the above discussed issueschange in refractive index, change in composition of material, change of the $d_{\mathrm{p}}$ of the incident wave into the material and the non-linearity region of the Eq. 2.

Despite the disadvantages of the FT-IR-ATR technique in studies of oxidation, in terms of being opened to the environment during the measurement in the conformation used, it allows us to directly observe the changes in the reaction with relatively low level of sample preparation. For thicker or stiffer samples (e.g. at lower temperatures) the diffusion of oxygen into the layer of the film may pose a problem, though.

\section{Materials and methods}

\subsection{Inorganic fines}

Calcium hydroxide as a representative of known bitumen oxidation inhibitors was chosen (Merck Millipore). $\mathrm{CaCl}_{2}$ (Merck Millipore) was used as a representative of deicing chemicals potentially accumulating inside AC upon drying of the pavements exposed to deicing brines. Iron (III) chloride hexahydrate $\left(\mathrm{FeCl}_{3} * 6 \mathrm{H}_{2} \mathrm{O}\right)$ (Merck Millipore) was chosen as a representative of a strong catalyst. Additionally, we wanted to investigate if the deactivation of a $\mathrm{FeCl}_{3}$, would be possible by means of a secondary reaction between the catalyst and a third reagent. We chose copper powder (Merck Millipore, 2703) as a third 
reagent, knowing that the reaction between $\mathrm{FeCl}_{3}$ and $\mathrm{Cu}$ in a water based solution is spontaneous. Additionally, the copper powder was studied both without and with bitumen in the measurement set-up as a reference.

\subsection{Sample preparations}

Paving grade bitumen of a penetration grade $70 / 100$ $\left(\right.$ Pen $=76 \mathrm{dmm}$; Softening Point $\left.=48.4{ }^{\circ} \mathrm{C}\right)$ was used in the study. A stainless steel ring of $0.5 \mathrm{~mm}$ thickness, inner diameter of $5 \mathrm{~mm}$ and outer diameter of $10 \mathrm{~mm}$ was used to cast the bitumen $0.5 \mathrm{~mm}$ thin film samples inside of it, similarly as reported by Karlsson et al. [23].

The test combinations discussed and abbreviations used for them in this article are listed in Table 1. For the homogenous bitumen specimen (B), we used a hot spatula to smear the bitumen onto the ring, we cooled the film down and trimmed the excess with the hot spatula, where a non-stick silicon paper was used under the bitumen and the ring. The specimens were conditioned at $5{ }^{\circ} \mathrm{C}$ for a period of $20 \mathrm{~min}$ to assure sufficient firmness during the transfer to the heated stage. The bitumens mixed with inorganic materials (heterogeneous specimens) were first scaled on a Petri dish, and heated for $5 \mathrm{~min}$ at $80{ }^{\circ} \mathrm{C}$ to liquefy the bitumen before a chosen agent was added into the droplet and stirred with a spatula. The mixture was then casted onto the ring and excess was removed with a hot spatula $\left(\mathrm{BCaCl}_{2}, \mathrm{BCa}(\mathrm{OH})_{2}, \mathrm{BFeCl}_{3}\right.$ and $\mathrm{BFeCl}_{3} \mathrm{Cu}$ ). The number of minimum three repetitions was performed on each system.

In the experiment using a fine copper powder, the bitumen was either casted (BCu), or mixed with $\mathrm{FeCl}_{3}$ $\left(\mathrm{BFeCl}_{3} \mathrm{Cu}\right)$ as described above, and then casted. Just before starting the measurement, a portion of the copper powder was pressed onto the surface of the bitumen with tweezers and the specimen was scaled. At the heating stage of the equipment, before the measuring temperature was reached, the copper was immersed in the prepared casted bitumen or bitumen$\mathrm{FeCl}_{3}$ mixture.

\subsection{FT-IR ATR measurements}

The Fourier Transform Infrared spectrometer Nicolet $^{\mathrm{TM}}$ iS50 [32] with GladiATR (equipped in diamond crystal) accessory was used [33]. The temperature sensor type uses the low drift and high stability 3 wire platinum Resistance Temperature Detection system, with an accuracy of temperature control to $+/-0.5 \%$. An OMNIC ${ }^{\mathrm{TM}}$ spectra software with an ATR correction was used during the data collection (32 scans and resolution of $4 \mathrm{~cm}^{-1}$ ).

Typically, the temperature of the plate was set to $163{ }^{\circ} \mathrm{C}$ and a background was collected. Then the temperature was decreased in order to place the ring with the casted bitumen in place and the temperature was set back to $163{ }^{\circ} \mathrm{C}$. The change of state from a casted film to liquid during the heating assures good contact between the sample and the prism, which is crucial for repeatability of FT-IR-ATR repeatability. When this temperature was reached, a first spectra $\left(t_{0}\right)$ was collected, while the succeeding spectra were recorded in 4-min intervals. The temperature stability after the $t_{4}$ was within $162.9-163.2{ }^{\circ} \mathrm{C}$. After $60 \mathrm{~min}$ $\left(t_{60}\right)$, the last spectra was collected and the temperature was switched off.

\subsection{Data processing}

In an intention to calculate the areas under the characteristic peaks which have been previously

Table 1 The list of the tested combinations with provided concentrations of the inorganic components

\begin{tabular}{|c|c|c|c|c|}
\hline Sample code & Inorganic component & Of bitumen wt $\%$ & Of bitumen wt $\%$ by dry salt & Results \\
\hline $\mathrm{B}$ & - & $\mathrm{n} / \mathrm{a}$ & $\mathrm{n} / \mathrm{a}$ & Figures 1,2 and 3 \\
\hline $\mathrm{BCaCl}_{2}$ & $\mathrm{CaCl}_{2}$ & 0.60 & 0.60 & Figure 2 \\
\hline $\mathrm{BCu}$ & $\mathrm{Cu}$ & 0.60 & $\mathrm{n} / \mathrm{a}$ & Figure 4 \\
\hline $\mathrm{BFeCl}_{3}$ & $\mathrm{FeCl}_{3} * \mathrm{H}_{2} \mathrm{O}$ & 1.01 & 0.60 & Figures 2 and 3 \\
\hline $\mathrm{BFeCl}_{3} \mathrm{Cu}$ & $\mathrm{FeCl}_{3} * \mathrm{H}_{2} \mathrm{O}+\mathrm{Cu}$ & $1.21+1.53$ & 0.72 & Figure 4 \\
\hline $\mathrm{Cu}$ & $\mathrm{Cu}$ & $\mathrm{n} / \mathrm{a}$ & $\mathrm{n} / \mathrm{a}$ & Figure 4 \\
\hline $\mathrm{BCa}(\mathrm{OH})_{2}$ & $\mathrm{Ca}(\mathrm{OH})_{2}$ & 0.59 & 0.59 & Figure 5 \\
\hline
\end{tabular}




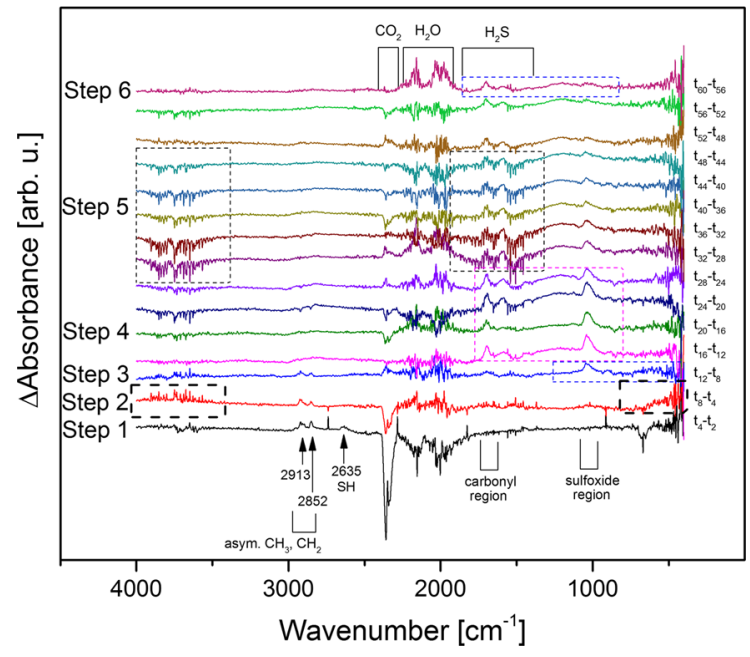

Fig. 1 The presentation of changes in spectra during aging of virgin bitumen (B) between each measuring point with marked indicators of discussed reaction steps: 1 -increase of the signal characteristic for thiols and asymmetric stretch in alkanes indicating decomposition of sulfides; 2 -formation of disulfide bond $\left(540 \mathrm{~cm}^{-1}\right)$ and rippling associated with hydrogen peroxide formation (in rectangles); 3-increase of the signal in the sulfoxide range with a minuscule change in the carbonyl range and increase in the farIR region indicative of disulfide formation; 4-simultaneous increase of the signal in the aromatic, sulfoxide and carbonyl region, and the wide heterogeneous atom shoulder $1100-1300 \mathrm{~cm}^{-1}$ (fast stage); 5release of the gaseous compound of a spectra similar to hydrogen sulphide or water indicating decomposition of disulfides and condensation; 6-steady state oxidation causing increase of the signal in the carbonyl region. The lines have been vertically translated for increased clarity

described in literature [6], an attempt at eliminating the noise level in the spectra was made. The initial plan was not to smoothen the spectra, but to remove the noise in order to obtain the bitumen signal. However, as we tried to identify the patterns in the noise an observation was made that the noise was occurring in pulses and the position of the noise was not consistent at different stages in the measurements (Fig. 1). The pattern was found, in which certain ripples on the spectra were forming during the formation of peaks characteristic for the aging of bitumen (e.g. within sulfoxide region). When the noise spectra was isolated from the collected spectra we realised that what we previously considered as noise, was most likely a signal from gaseous compounds such as water, hydrogen peroxide [34], hydrogen sulphide [30] and volatile organic compounds [35].
In addition to the qualitative analysis of the raw spectra, the data were first pre-processed in two ways. In the first approach, denoted as the time differential, from each of the spectra collected at $t_{\mathrm{x}}$ (or $n_{\mathrm{i}}$, where $n$ is the number of step in time), a baseline (spectra collected at $t_{0}$ or $n_{1}$ ) was subtracted (Figs. 2b, 5c). In the second approach, denoted as the step differential, from each of the spectra collected at $n_{\mathrm{i}}$, a baseline defined as the spectra at $n_{\mathrm{i}-1}$ was subtracted. Such step differential spectra is presented in Figs. 3, 4 and 5a. Both of those results were then divided by time in seconds between two considered measurements, and a series of spectrograms, plots depicting the magnitude of the change of percent Transmittance [\%T] in time at certain frequency, was prepared for all previously mentioned data (Figs. 2, 3, 4, 5).

Figure 2c, d depict the spectrograms with the time differential approach while Figs. 3, 4 and 5a present the spectrograms with the step differential approach.

Similar evaluation of the reaction mechanism as in Fig. 1 was presented for $\mathrm{BFeCl}_{3}$ and $\mathrm{BFeCl}_{3} \mathrm{Cu}$ in Figs. 6 and 7. The scale of the intensity change of the peaks was kept identical in Figs. 1, 6 and 7, therefore the figures should be comparable.

It is important to note that there were data quality problems with the $t_{0}$ spectra due to experiment set-up limitations. Although the equipment stops heating the plate when a certain temperature is reached, the temperature of the plate still increases slightly $\left(1-2{ }^{\circ} \mathrm{C}\right)$, and when left undisturbed the actual temperature set is reached at about $t_{4}$. The extra heat can be withdrawn faster than the equipment stabilizes itself, by touching the heating stage for a short moment with a metal spatula, but this is a trial and error approach. Therefore, in a few cases, the actual temperature was not $163{ }^{\circ} \mathrm{C}$ in those two first measurements, but slightly higher. This results in less dense material, more IR transmittance observed as less absorbance, and incompatibility with the collected background. In these cases, the $t_{0}$ measurement was replaced with $t_{2}$ or $t_{4}$ spectra as a baseline and an empty entry is then presented in the Figs. (3b, 5a).

The collected infrared spectra as well as results of the processing of the spectra were compared against spectra available in the databases [30] for the purpose of compound/functional group identification. A summary of spectral characteristics of analogue compounds is presented in Table 2. 


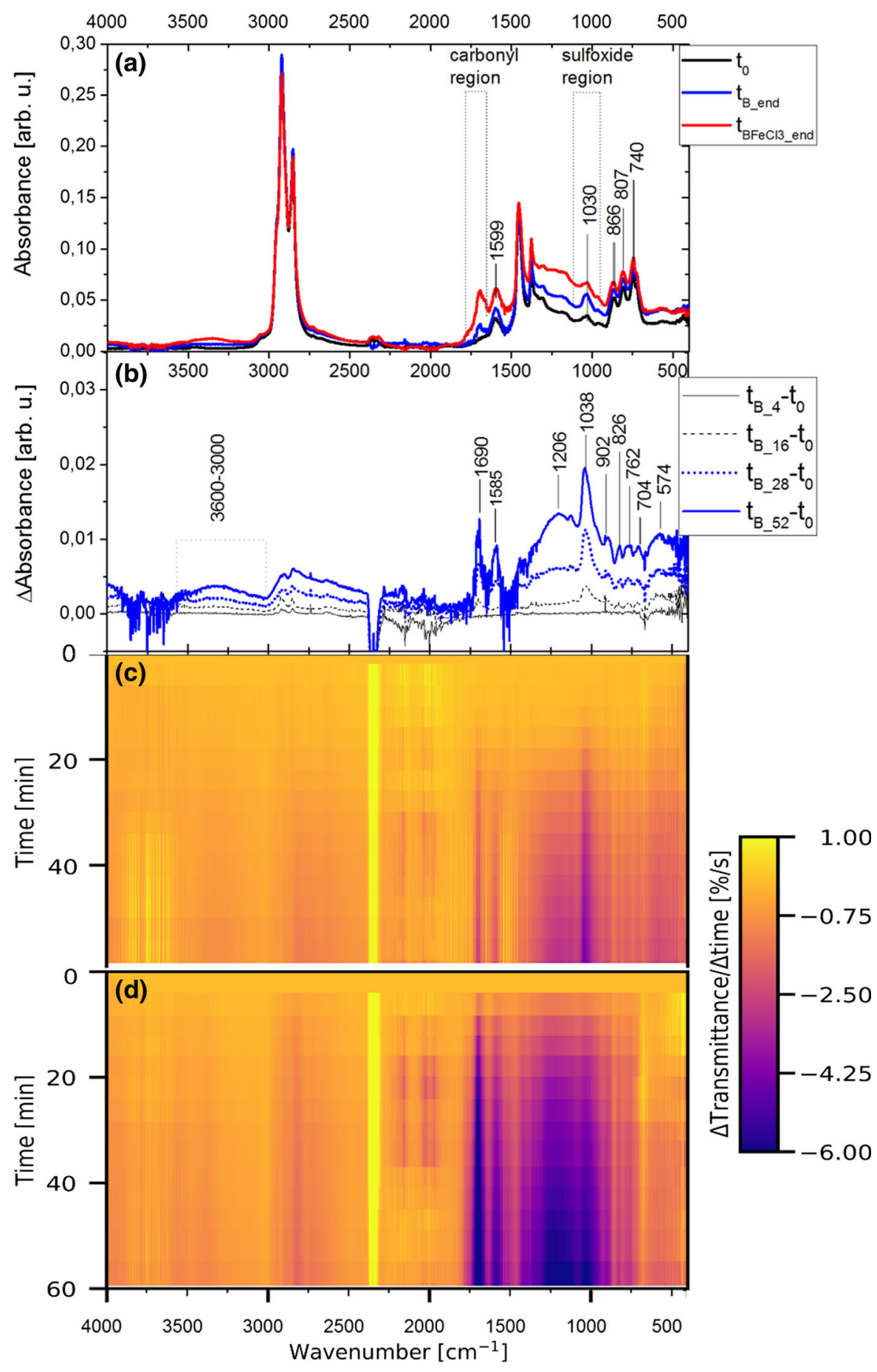

Fig. 2 a The FT-IR spectra of bitumen (B) at $t_{0}$ (black line), $t_{60}$ (blue line) and at $t_{60}$ when in contact with $\mathrm{FeCl}_{3} * 6 \mathrm{H}_{2} \mathrm{O}$ $\left(\mathrm{BFeCl}_{3}\right), \mathbf{b}$ the time differential spectra from raw bitumen aging experiment (B) at chosen times with identified characteristic changes in absorbance, c Spectrogram of the change in Transmittance spectra of bitumen (B), during exposure to air at $163{ }^{\circ} \mathrm{C}$ measured by ATR-FT-IR as compared to the reference at $t_{0}$, $\mathbf{d}$ Spectrogram of the change in Transmittance spectra of bitumen on contact with $\mathrm{FeCl}_{3} * 6 \mathrm{H}_{2} \mathrm{O}\left(\mathrm{BFeCl}_{3}\right)$, during exposure to air at $163{ }^{\circ} \mathrm{C}$ measured by ATR-FT-IR as compared to the reference at $t_{0}$ 


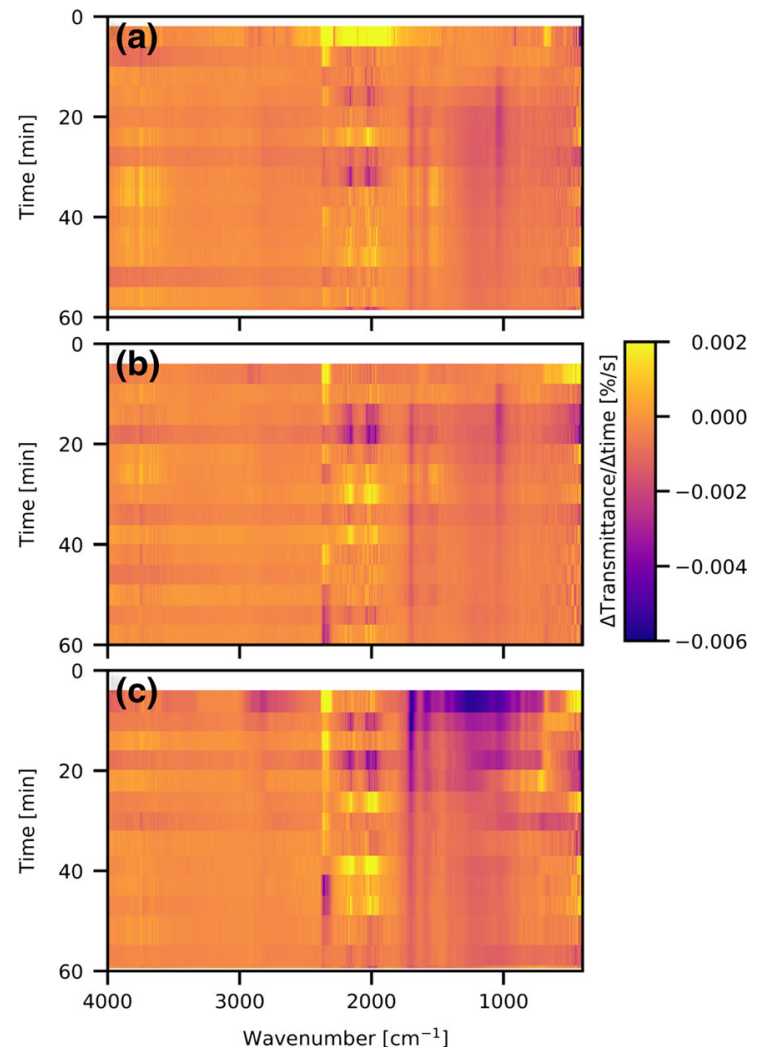

Fig. 3 Spectrogram of the change in Transmittance spectra of a bitumen (B), b bitumen with $\mathrm{CaCl}_{2}\left(\mathrm{BCaCl}_{2}\right)$, $\mathbf{c}$ bitumen with $\mathrm{FeCl}_{3}\left(\mathrm{BFeCl}_{3}\right)$ during exposure to air at $163{ }^{\circ} \mathrm{C}$ measured by ATR-FT-IR as compared to the spectra at previous time step

\section{Results and discussion}

The majority of research is based on the analysis of either laboratory-aged bitumen or bitumen extracted from contact with aggregates, or laboratory-aged in the presence of inorganic material and extracted from it for analysis $[5,7,9,11,14,22,36]$. Typically the first evaluation point is chosen at $60 \mathrm{~min}$. In contrast to that we present here, an insitu following of the reaction between bitumen and oxygen, which is presented in Fig. 1. We then, based on literature review and hereby presented preliminary results, postulate the reactions occurring during the first $60 \mathrm{~min}$ of tested bitumen's exposure to air based on the step-differential plots (Fig. 3). In Figs. 3, 4 and 5 we compare the spectrograms prepared on the basis of data collected from all of the heterogeneous systems to visualize the change in mechanism and kinetics of reaction.

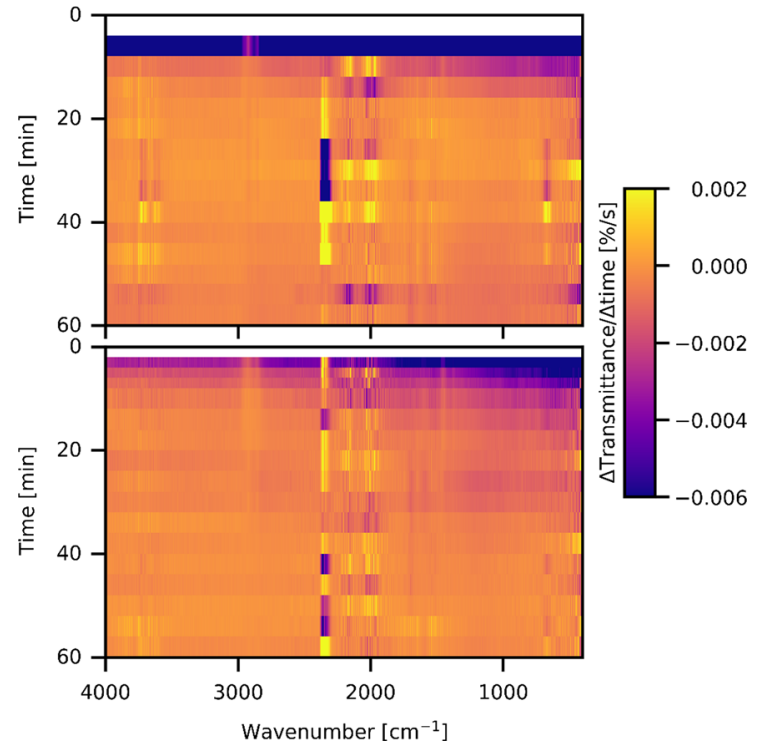

Fig. 4 Spectrogram of the change in Transmittance spectra of bitumen with $\mathrm{FeCl}_{3}$ and $\mathrm{Cu}\left(\mathrm{BFeCl}_{3} \mathrm{Cu}\right)(u p)$ and bitumen with $\mathrm{Cu}(\mathrm{BCu})($ down $)$, during exposure to air at $163{ }^{\circ} \mathrm{C}$ measured by ATR-FT-IR as compared to the spectra at the previous time step

Petersen et al. [24] investigated the oxidation of organosulfur compounds in the petroleum residues both by laboratory aging on the gas chromatography column and by analysis of field extracted samples. It is important to note that the oxidative agent chosen was hydrogen peroxide, as their aim was to investigate the product of a maximum oxidation. However, the choice of such a strong oxidative agent may lead to misinterpretation. Sulfides do not readily oxidize to sulfoxides and require peroxide presence as a propagator of reaction $[6,24,37]$. The petroleum crudes have been reported to consist of a variety of sulfides and thiols [24]. Yet, the majority of the focus of the analysis of oxidative aging of sulfur compounds in bitumen falls on the oxidation of sulfides. Therefore, it has been assumed that a naturally forming peroxide within the bitumen catalyzes the oxidation [6, 24]. Products of this reaction result in a very slight increase in molecular weight due to the addition of up to two molecules of oxygen. On the other hand, in the studies of changes in Molecular Weight Distribution (MWD) upon oxidation by air analyzed with Gel Permeation Chromatography, it is well documented that the MWD becomes bimodal. While this may be due to the agglomeration of molecules with increased polarity, it is thought to also indicate that oligomerization is 


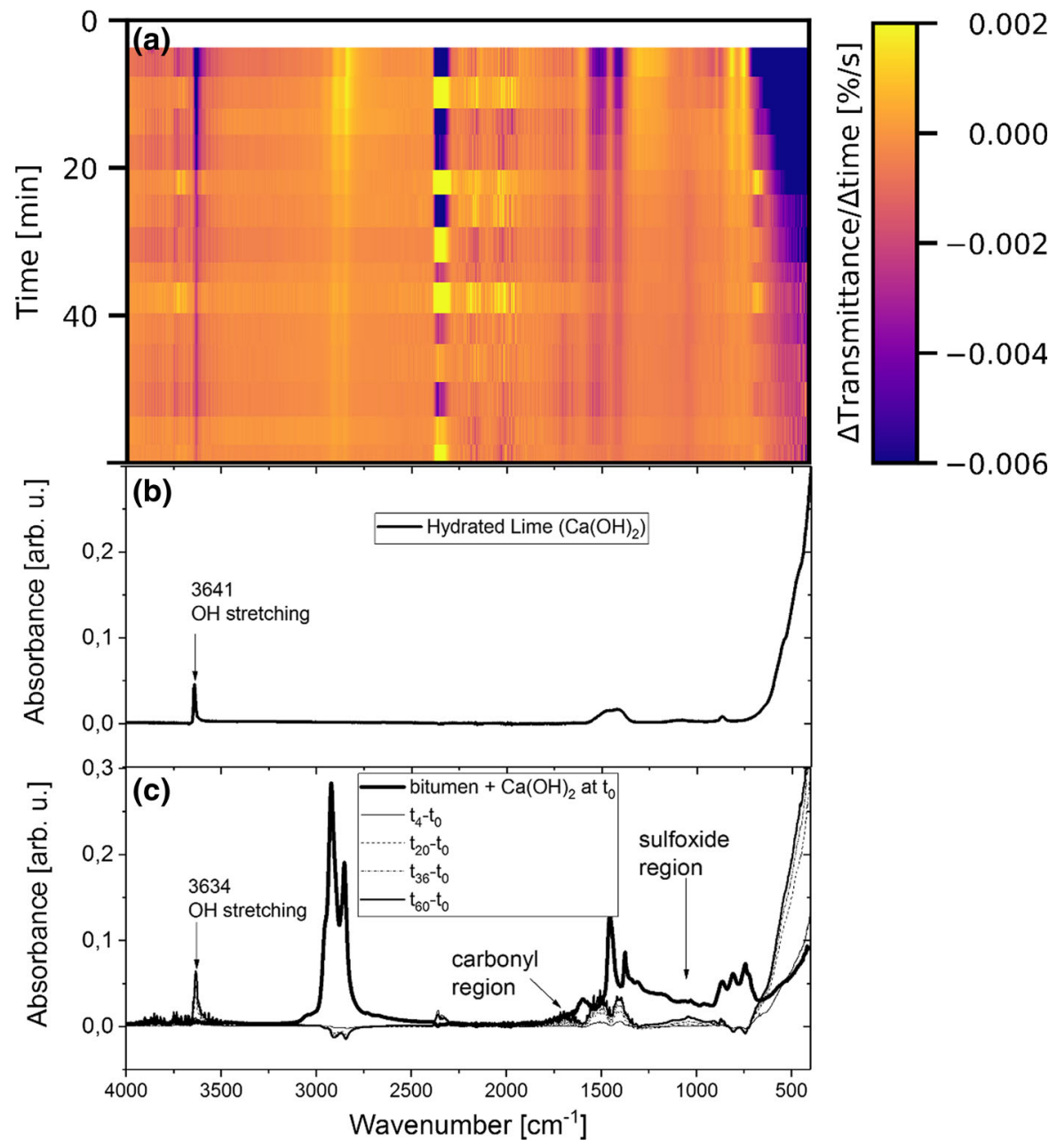

Fig. 5 Spectrogram of the change in Transmittance spectra of bitumen with $\mathrm{Ca}(\mathrm{OH})_{2}\left(\mathrm{BCaOH}_{2}\right)$ during exposure to air at $163{ }^{\circ} \mathrm{C}$ measured by ATR-FT-IR as compared to the spectra at previous time step (a), compared to the spectra of hydrated lime

occurring in the bitumen upon oxidation parallel to a settled uptake of singular molecules of oxygen into the mass [38-40]. However, examining the step differential spectra we clearly see that the oxidation of bitumen is a stepwise reaction (Fig. 1) in both a homogenous or in a heterogeneous specimens.

\subsection{The progress of the oxidation reaction in homogenous bitumen specimen}

The sulfur content of bitumen can vary between 0.5 and $7 \%$ depending on the origin of the crude oil and refining conditions [37]. The investigation of sulfur types in bitumens during the Strategic Highway powder (b) and a demonstration of the increase in signal of hydrated lime in the $\mathrm{BCa}(\mathrm{OH})_{2}$ experiment based on the time differential analysis (c)

Research Program, focused on identification of sulfides, thiophenes, and sulfoxides by selective oxidation techniques. The presence of thiols in that research was investigated based on a presence of a very weak characteristic peak at $2400-2600 \mathrm{~cm}^{-1}$ for thiols and an analysis of their oxidation products by IR technique and determined to be almost absent [37]. Even if we assume that the concentration of thiols is insignificant, because the sulfides comprise the majority of the sulfur species in the bitumen, it is highly possible that upon heating, thermal decomposition of sulfides leading to the formation of thiols occurs before the oxidation of sulfides in air [41, 42]. 


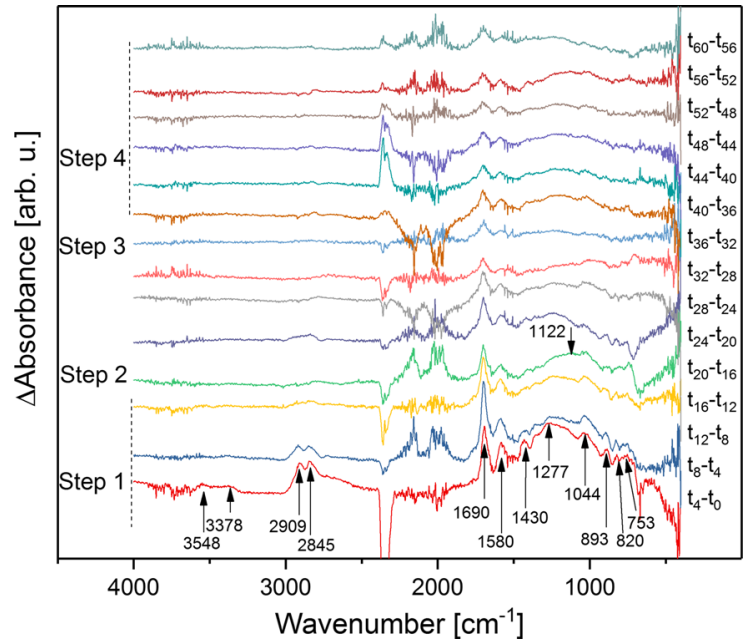

Fig. 6 The presentation of changes in spectra during aging of bitumen on contact with $\mathrm{FeCl}_{3} \quad\left(\mathrm{BFeCl}_{3}\right)$ between each measuring point with marked indicators of discussed reaction steps for this system: 1-simultaneous formation of alkenes (753, 820 and $893 \mathrm{~cm}^{-1}$ ), sulfoxides, sulfones, carbonyl, alkyls, alcohols (1277 and $3548 \mathrm{~cm}^{-1}$ ) and potentially peroxide signal $\left(3378 \mathrm{~cm}^{-1}\right) ; 2$ - shift towards formation of aliphatic sulfones $\left(1122 \mathrm{~cm}^{-1}\right)$ [24], while $-\mathrm{CH}_{2^{-}}$signal increase stops; 3 petering out of the alkene formation and lower sulfoxide formation; 4-the sulfoxide and carbonyl formation similar as in virgin bitumen. The lines have been vertically translated for increased clarity

Some of the reactions proposed to occur during the decomposition of sulfides (Step 1, Fig. 1) can be thus written:

$\mathrm{R}^{1}-\mathrm{CH}_{2}-\mathrm{S}-\mathrm{R}-\mathrm{CH}_{3} \rightarrow \mathrm{R}^{1}-\mathrm{CH}_{2} *+\mathrm{S}-\mathrm{R}-\mathrm{CH}_{3}$

$\mathrm{R}^{2}-\mathrm{CH}_{3}+* \mathrm{~S}-\mathrm{R}-\mathrm{CH}_{3} \rightarrow \mathrm{R}-\mathrm{CH}_{2} *+\mathrm{CH}_{3}-\mathrm{R}-\mathrm{SH}$

Incidentally, at the very beginning of our B experiment, we observed a very weak peak formation at $2636 \mathrm{~cm}^{-1}$, typically characteristic for thiols. The confidence in the significance of this peak is low. However, it is accompanied by the increase of the signal in band characteristic for asymmetric stretching vibrations of methyl group $\left(\mathrm{CH}_{3}\right)$ and methylene bridge $\left(\mathrm{CH}_{2}\right)$ (Fig. 1), more specifically with increasing ratio of $\mathrm{CH}_{2} / \mathrm{CH}_{3}$. Such increase could be the result of e.g. the recombination reaction:

$\mathrm{R}^{2}-\mathrm{CH}_{2} *+\mathrm{R}^{2}-\mathrm{CH}_{2} * \rightarrow \mathrm{R}^{2}-\mathrm{CH}_{2}-\mathrm{CH}_{2}-\mathrm{R}^{2}$

This could be indicative of a formation of thiols in this early stage of reaction.

It was demonstrated previously, that the addition of peroxide into the reaction system increased the rate of

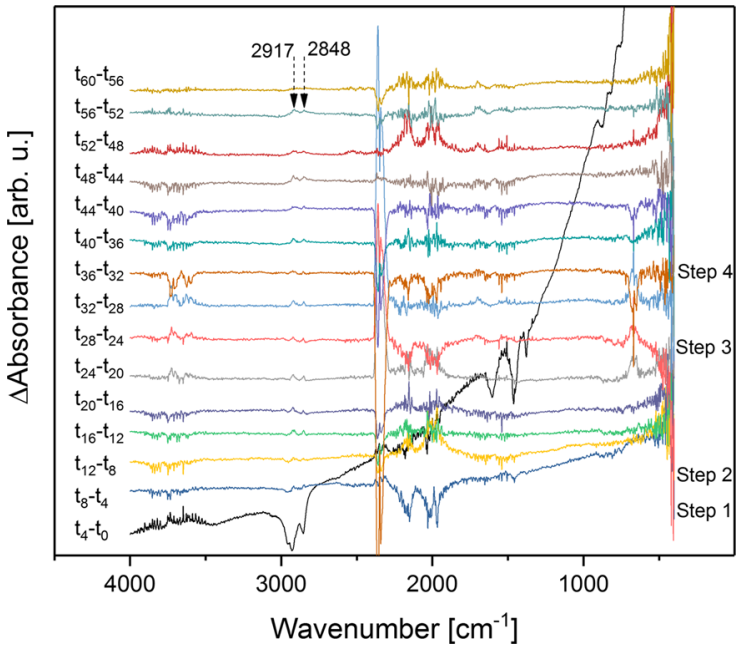

Fig. 7 The presentation of changes in spectra during aging of bitumen on contact with $\mathrm{FeCl}_{3}$ and $\mathrm{Cu}\left(\mathrm{BFeCl}_{3} \mathrm{Cu}\right)$ between each measuring point with marked indicators of discussed reaction steps for this system: 1 - The increase of the signal of copper and decrease of the signal of bitumen as the copper immerses into the sample $\left(\mathrm{t}_{4}-\mathrm{t}_{0}\right) ; 2$-aliphatic chain growth as $\mathrm{CH}_{2}$ - signal increases; 3-beginning of the formation of carbonyl; 4 - continued $\mathrm{CO}$ formation and evaporation of low molecular compounds indicative of condensation. The lines have been vertically translated for increased clarity

bitumen oxidation, but addition of free radicals in form of initiators did not increase the reaction speed, suggesting that it is not a free radical mechanism, but rather that oxidation is self-catalysed by peroxide molecules forming within the bitumen [6, 24]. If the peroxides, which would be unstable in storage, present in the bitumen would catalyse the reaction, we would not observe a delay of oxidation either in these experiments or in the low temperature aging studies [6]. The conclusion drawn from this analysis is that the peroxide species must form in the initial stage of oxidation in the system upon exposure to oxygen. Knotnerus [44] proposed that the analogue for the oxidation reaction in bitumen should be sought in 9,10-dihydroanthracene, which upon uptake of oxygen would form anthracene and hydrogenperoxide or 9-hydroxyperoxide-10-hydroanthracene [6]. The conclusion was drawn based on the similar molar uptake of oxygen per assumed mol of average bitumen used in that study, that 9,10-dihydroanthracene is a correct analogue. However, there were one decade differences in the oxygen uptake between the bitumens e.g. Middle East and Venezuelan one [44]. The later was more in line with oxygen uptake in analogous 


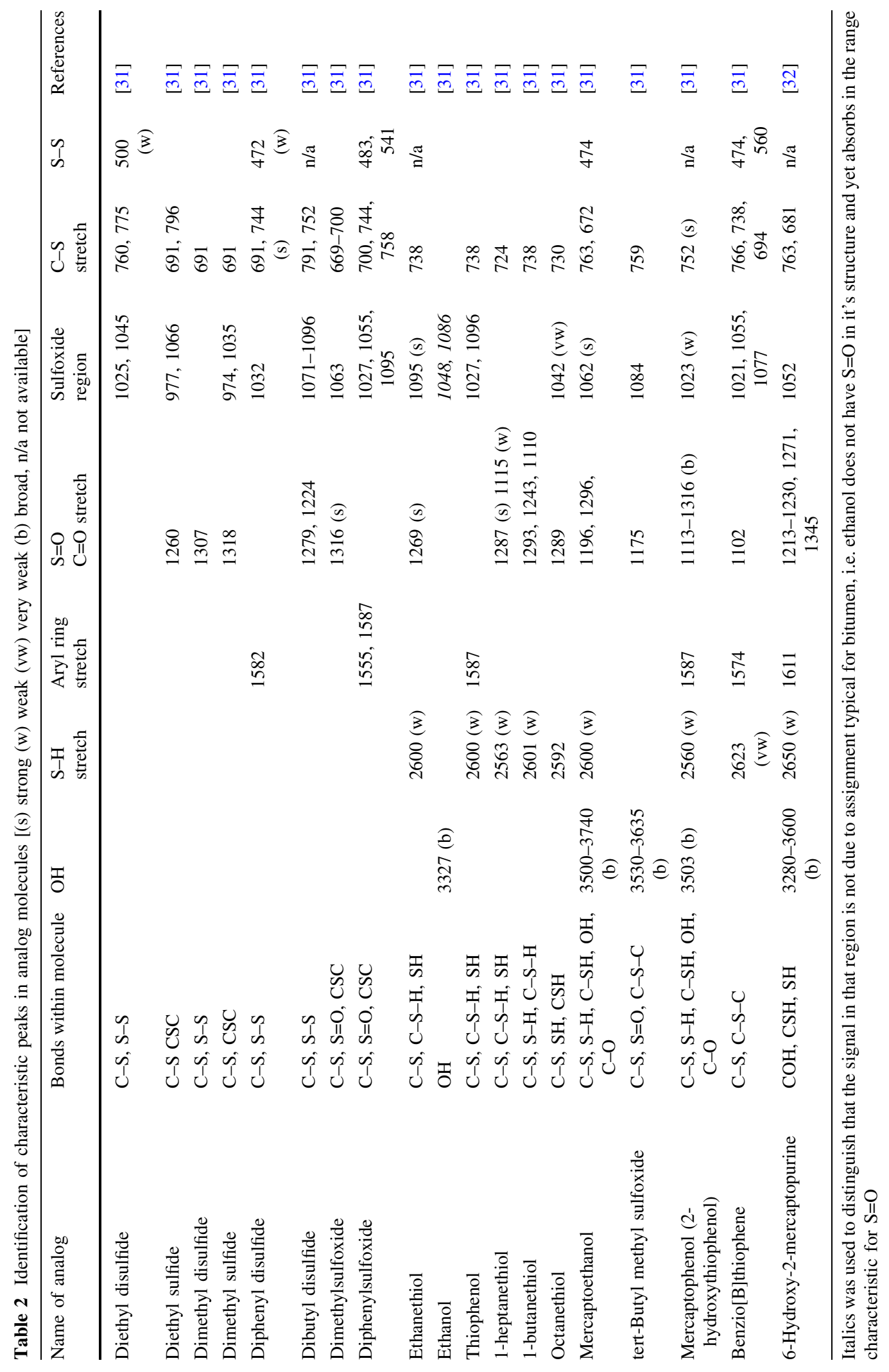


compounds such as 3-methyltetrahydrothiophene or 3-nonylbenzothiophene, which are both containing sulphur in their structure. Our experimental design did not consider originally, that the mechanism of reaction could be different. We did not include the array of crude oil sources in our investigations and we rather focused on analysis of paving grade bitumen available on the local market. If the formation of anthracene was occurring, negative signals associated with such transformation should appear [31]. If the organic hydroxyperoxide intermediates were formed, signals at about $3400 \mathrm{~cm}^{-1}$ should appear [45] which are absent in $\mathrm{B}$ system, but may be observable for $\mathrm{BFeCl}_{3}$.

Intriguingly, the oxidation reaction of thiols in air (Step 2, Fig. 1) can occur with the formation of a hydrogen peroxide and disulfides as well, which can essentially be called dimerization [43]:

$$
\begin{aligned}
& 2 \mathrm{RSH}+\mathrm{O}_{2} \rightarrow \mathrm{RSSR}+\mathrm{H}_{2} \mathrm{O}_{2} \\
& 4 \mathrm{RSH}+\mathrm{O}_{2} \rightarrow 2 \mathrm{RSSR}+\mathrm{H}_{2} \mathrm{O}
\end{aligned}
$$

However, in the high $\mathrm{pH}$ range, a path leading to sulfinic $\left(\mathrm{RSO}_{2} \mathrm{H}\right)$ and sulfonic acids $\left(\mathrm{RSO}_{3} \mathrm{H}\right)$ is predominantly observed [44]. Thus in the presence of basic AC fillers, such as hydrated lime [45], at this stage of reaction a different path should be observed. In Fig. 5 we can see that the signal in the sulfoxide region increases continuously throughout the $60 \mathrm{~min}$ period, unlike in other systems. $\operatorname{In} \mathrm{BCa}(\mathrm{OH})_{2}$ it is hard to determine any disulphide signal formation as those overlap with the signal of hydrated lime.

Additionally, when tracing the reaction insitu, one should also expect to observe the signals from the side products. The water, hydrogen peroxide and hydrogen sulfide in their gaseous state express a set of characteristic absorption bands in the form of ripples (Fig. 1). Therefore, we proposed that future investigations should control the air flow and analyze the gases emitted by the system during the reaction in order to even better understand the reaction (Fig. 6). In this analysis we performed best possible assignment.

Nevertheless, in the considered system the created hydrogen peroxide would be readily available to mediate the oxidation of sulfides. The observation of a change consistent with reactions (10) and (11) would be in the increase of the spectra in the far IR region (400-500 $\left.\mathrm{cm}^{-1}\right)$, characteristic for the formation of disulfides (Table 2) and mentioned ripples within that region. Unfortunately, both thiol and disulfide characteristic peaks are very weak, and in case of disulfides, not sharp. During the analog compound analysis, we additionally observed that the peak at 1025-1096 $\mathrm{cm}^{-1}$ in disulfides [30], as compared to their thiol analogues, increases in intensity relatively. Therefore, the initial increase of absorbance in the so-called sulfoxide region might initially rise due to the formation of disulfides.

The sulfoxide group concentration is typically determined from the IR spectra and compared against the calibration curves prepared using analogues. However, if the absorbance in the region increases without an actual introduction of oxygen atom into the structure of bitumen, the viscosity, which has been proven to increase with the increase of polar compounds [6], would not rise as dramatically. In fact, the viscosity in bitumen has been demonstrated to increase faster with the growth of signal within the carbonyl region than in the sulfoxide region [6].

Further proof of reaction (10) and (11) hypothesis lies in the oligomerization observed by GPC in oxidized bitumen. This phenomenon has been observed [38-40], but suggested as originating from unspecified form of elimination reaction releasing a water molecule [46]. A dimerization of carboxylic acids was proposed for a model. However, at this early stage in reaction no visible formation of carbonyl signal formation was observed. We hereby propose an alternative explanation for this change (Eqs. 7-11).

The following step in the reaction should focus on oxidation of disulfides as the system remains in high temperature conditions, as well as interaction of peroxide with existing sulfides (Steps 3-5, Fig. 1).

In Step 3, an increase of the signal within the sulfoxide region is observed with a maximum at $1044 \mathrm{~cm}^{-1}$. On the other hand, the increase of the signal in the sulfoxide region has been also observed for alcohols and mercaptanols (Table 2). The hydro$\mathrm{xyl}(\mathrm{OH})$ group signal within $3000-3600 \mathrm{~cm}^{-1}$ is absent in step differential analysis, but visible in the time differential analysis (Fig. 2b). This cannot be assigned without a doubt to the $\mathrm{OH}$ bond. However, let us consider the possibility that in Step 3 (Table 2), we would obtain an alcohol group as a precursor for the ketone bond (observed at $1690 \mathrm{~cm}^{-1}$ ). A disproportionation reaction between alkanes and hydrogen peroxide has been reported to provide peroxides, alcohols and ketones as a product [47] in acetonitrile solutions. These peroxides would be available for 
reaction with sulfides producing more alcohols and ketone precursors. We observed a ketone band being formed in the following Step 4, alongside the further increase of the sulfoxide signal. Based on the mechanism of sulfoxide formation [48], we could propose that the reactions in those steps are:

$$
\begin{aligned}
& \mathrm{RH}+\mathrm{H}_{2} \mathrm{O}_{2} \rightarrow \mathrm{ROOH}+\mathrm{ROH}+\mathrm{RO} \\
& \mathrm{R}^{\prime}-\mathrm{S}-\mathrm{R}^{\prime \prime}+\mathrm{ROOH} \rightarrow \mathrm{R}^{\prime} \mathrm{SOR}^{\prime \prime}+\mathrm{ROH} \\
& \mathrm{RSOR}+\mathrm{ROO}^{-} \rightarrow \mathrm{RSO}_{2} \mathrm{R}+\mathrm{RO}^{-}
\end{aligned}
$$

In the reaction of the mixture of compounds, we should expect that all paths - the formation of disulfide, sulfoxide, ketone and hydroxyl bonds-may be simultaneously happening.

From an analysis of the changes in spectra between $t_{28}$ and $t_{48}$ (Step 5), the formations of ripples are assigned to the $\mathrm{H}_{2} \mathrm{~S}$, which has been reported as one of the by-product of disulphide decomposition at high temperatures [42]. However, the signal is most likely overlapping with the $\mathrm{H}_{2} \mathrm{O}$ absorption bands, which can be coming from a variety of reactions. In this step, further oxidation of sulfides, decomposition of disulfides, and formation of ketone bonds is observed. All of those processes may lead to the increase of the signal in the sulfoxide region.

In the last step, we observe the minuscule changes to the sulfoxide region, while the carbonyl signal continues to increase. Additionally, it was postulated previously that the decomposition of sulfoxides to sulfinic acids occurs, which when in a disproportionation reaction forms disulfides and thiosulfonates [49].

In summary, sulfides decompose to thiols, which form disulfides creating peroxides. This process is a precursor for further oxidation of sulfides and formation of ketones. However, because aging in our system occurs at the relatively high temperature of $163{ }^{\circ} \mathrm{C}$, we cannot exclude the decomposition of disulfides and sulfoxides taking place in parallel.

Observing the reaction at lower temperatures and at more frequent scans should improve the resolution and perhaps allow us to observe even more intermediate steps.

\subsection{The progress of the oxidation reaction in heterogeneous specimens}

Interestingly, we are able to observe and report here for the first time the initial delay in formation of the sulfoxide and carbonyl signal during the short term aging [6]. Additional observation is made that the sulfoxide signal increases first before the carbonyl one. Previous exsitu measurements assumed that the increase of the intensity of both signals occurs starting from $t_{0}$, and the majority of correlations between rheological response and FT-IR spectra are based on that assumption [36]. By examining the changes in the time differential spectra of the raw bitumen during the first 60 min of oxidation, we can clearly see that there is a time period during which the chemical changes cannot be observed in the so-called carbonyl and sulfoxide region with FT-IR-ATR (Fig. 2) in raw bitumen.

This type of delay was also previously observed during the low temperature aging of bitumen [6]. However, it was assumed that the lack of delay at high temperatures indicated a different aging mechanism. Based on our observations, we suggest that the mechanism may be similar: it is most likely the rate of the reaction that changes with the temperature.

Furthermore, we observed in our experiments that the magnitude of a change in transmission varies depending on the composition of the tested specimen (Figs. 2, 4, 5). As was expected, the decrease in transmittance, within the regions characteristic of aging, in the experiment $\mathrm{BFeCl}_{3}$ is much more severe than in any of the other tested combinations. The identification of the system prone to more aging is easy when comparing the extremes, such as $\mathrm{B}$ and $\mathrm{BFeCl}_{3}$ (Fig. 2a, c).

Upon introduction of the catalyst (Fig. 3c), we observe that the time delay of aging is much shorter than in the reference experiments. In fact an array of signals consistent with various oxidation products is visible already at $t_{4}$ for $\mathrm{BFeCl}_{3}$. This includes new signals in comparison to $\mathrm{B}$ experiment, such as from alkenes otherwise indicating aromatization (Fig. 6).

During the experiment $\mathrm{BFeCl}_{3}$, we observe no inhibition period for oxidation reaction and the aging process progresses violently with time (Fig. 3c). It is not possible to determine if the thiols are created, because at $\mathrm{t}_{4}$ we already have a formation of peaks in sulfoxide and carbonyl region, but also a broad peak at frequencies $2500-2750 \mathrm{~cm}^{-1}$. The reactions (7-11) are either happening at a much faster rate than in the $\mathrm{B}$ experiment or a different mechanism is preferred. Incidentally, the reaction (11) upon contact with $\mathrm{FeCl}_{3}$ has been reported to occur catalytically, but via 
different mechanisms and result in slightly different products [50]. Nevertheless, similar to other experiments, the changes in the sulfoxide region reach a certain end point, tough much later in time.

In Experiment $\mathrm{B}$ and $\mathrm{BCaCl}_{2}$ (Fig. 3), we can see that the change to the sulfoxide region is not uniformly developing over time. After the initial time delay, there seems to be a pulse of a gaseous product (either VOC [35], $\mathrm{H}_{2} \mathrm{O}$ or $\mathrm{H}_{2} \mathrm{O}_{2}$ ) after which an increase of the signal in sulfoxide region occurs and is tailed by an increase in the signal in the carbonyl region. In the light of these findings, a more detailed analysis of volatiles should be conducted to determine their composition at a given time during the reaction.

Notably, in the experiment $\mathrm{BCaCl}_{2}$ (Fig. 3b), we see a similar aging characteristic to that of the $\mathrm{B}$ experiment, which leads us to conclude that calcium chloride is not a catalyst, perhaps a slight inhibitor of the oxidation of bitumen as the rate of transmittance change is lower in this case.

In the case of $\mathrm{BCa}(\mathrm{OH})_{2}$ (Fig. 5) a challenge for the method was observed. The signal of calcium hydroxide continued to increase during the whole $60 \mathrm{~min}$ period, while overlapping the bitumen spectrum. One of the viable explanation is in the continuous densification of the specimen, which may be due to evaporation of VOCs in this particular setup.

\subsection{Copper as an inhibitor}

In the $\mathrm{BFeCl}_{3} \mathrm{Cu}$ (Figs. 4 and 7) experiment, the differential analysis indicates almost no changes in the sulfoxide region during the first aging hour. This would indicate that the copper deactivates the catalytic activity of $\mathrm{FeCl}_{3}$ towards the bitumen. The intensity increase between the first time steps is consistent with the increase of the signal of copper, which probably comes in partial contact with the prism. Between $t_{8}$ and $t_{4}$, there is a small increase of peak in the thiol characteristic region, but again not within the confidence limits to conclude. Afterwards, we observe gaseous pulses and a very low rate formation of carbonyl peaks, lower than those observed in the homogenous systems. This could indicate that the ketone formation reaction in the presence of $\mathrm{Cu}$ still proceeds but via a different mechanism. Additionally, in Fig. 7 we can observe that the only consistent signal increase throughout the reaction is increase of asymmetric stretching of $\mathrm{CH}_{2}$, which in our opinion indicates some oligomerisation.

The possible mechanism of the hindered oxidation of bitumen in experiment $\mathrm{BFeCl}_{3} \mathrm{Cu}$ can be explained either by a well-known phenomenon of adsorption of thiol compounds on the copper oxide surface $[51,52,53]$. The reference experiment was conducted to investigate the effect copper particles have on the aging characteristics of bitumen (BCu, Fig. 4). During that experiment $(\mathrm{BCu})$, the formation of the peak in the sulfoxide region was also almost completely hindered.

As a comparison, judging from the lack of signal increase in the sulfoxide region $\left(\mathrm{BFeCl}_{3} \mathrm{Cu}\right)$, it seems that the copper extracted the thiol or other organosulfur compounds from the pool of substances ready for oxidation by adsorbing them on its surface.

\subsection{Synthesis and implications}

In summary, we present the proof for the stepwise oxidation of tested bitumen which can be controlled by the proper choice of inorganic enhancers. Both the catalysis, inhibition and obstruction of catalysis were demonstrated in the above results.

Despite this finding being very promising, the rheological response of the bitumen oxidized in the presence and absence of the catalyst should be evaluated by employing appropriate measurements. As observed previously, not all types of interaction between air and bitumen lead to the significant increase in the signal in sulfoxide and carbonyl region, despite expressing a change in the rheological properties, such as air blowing [11].

However, as is visible in step differential spectrograms, the rate of reaction is not the same for all of the combinations. There is a clear change between the lengths of period of oxidation inhibition. The rate of reaction is also affected by the presence of impurities. Especially, in system $\mathrm{BFeCl}_{3}$, we see that the rate of reaction is much higher in the beginning and continues on the level which, in the homogenous system, could be considered as the fast rate. This research proves that the heating process during the recycling of the asphalt pavements may lead to the pronounced aging of fresh bitumen if the aggregate underwent deterioration due to the action of de-icing chemicals. Screening for chloride content in RAP material could be of vast importance to prevent otherwise unexplainable failures. 


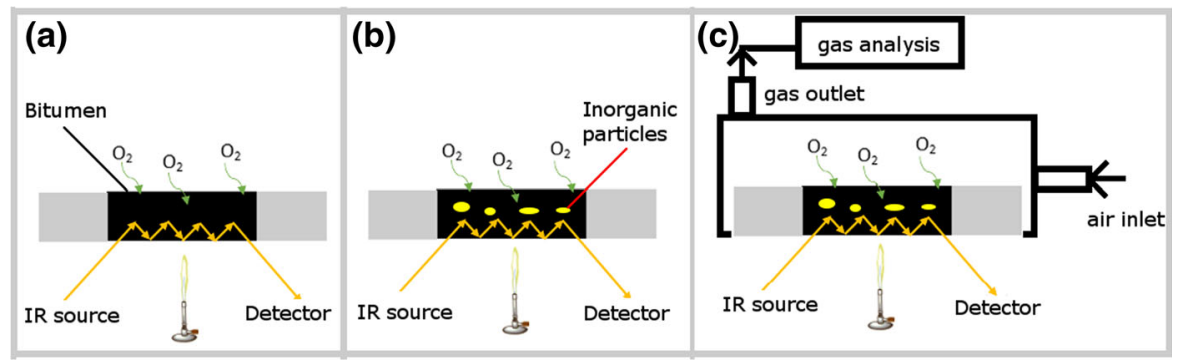

Fig. 8 Schematic representation of used measuring set-up for homogenous (a) and heterogeneous (b) specimens, followed by the schematic drawing of the proposed measuring set-up for enhanced oxidation reaction analysis

Additionally, it was demonstrated by the means of time-resolved insitu FT-IR-ATR spectroscopy that gaseous compounds are formed during the oxidation of bitumen. We are aware that for a chemical analysis, controlling the reaction atmosphere by supplying a stream of known oxygen concentration would be more ideal than the method we used. We propose that a different measuring set-up be used in the future (Fig. 8c) in which the ATR tool would be isolated from the ambient and in which gas inflow could be controlled and outflow analysed.

Furthermore, the catalytic activity of $\mathrm{FeCl}_{3}$ was demonstrated to be blocked by the introduction of copper into the system. The presence of copper was proved to inhibit the reaction of bitumen oxidation both alone and in the presence of a strong catalyst and a novel mechanism of aging inhibition was proposed on this basis.

Unfortunately, this research was conducted on one paving grade bitumen and we encourage the evaluation of hereby presented results on bitumen obtained from various crude oil sources.

\section{Conclusions}

This article presents the novel method of the insitu investigation of bitumen aging during the first $60 \mathrm{~min}$ of exposure to air at high temperatures. We have hereby demonstrated that a system in which bitumen is aged plays an important role. Selected inorganic compounds influencing the aging of the bitumen were tested, demonstrating both ambivalence, inhibition, and catalytic influence. We demonstrated that this method is promising in studies of interaction between bitumen, air and inorganic components in AC.

The oxidation of tested bitumen was demonstrated to be a stepwise reaction. Each of the steps was analyzed for heterogeneous system and a reaction series was suggested describing the observed changes. Therefore, it was proposed that the thiol species present in bitumen, or created during the decomposition of sulfides, are the precursor of the oxidation reaction. Their oxidation releases hydrogen peroxide, which then leads to the formation of sulfoxides and carbonyl containing species in the following oxidation steps. Inhibition of the whole series of reactions is proposed and demonstrated by the hindrance of the first step, namely by the immobilization of thiols by adsorption on copper particles.

The iron (III) chloride, even in the hydrated form, was identified as a risk factor in the recycling of the asphalt concrete due to its catalytic activity in the oxidation reaction. However, by the introduction of copper into the bitumen the oxidation was inhibited.

Finally, it is extremely challenging to track the changes of one molecule in bitumen, which is postulated to comprise thousands of different types of molecules. We acknowledge the fact that our experimental design was limited and did not explore every aspect of the reaction. Nevertheless, this article presents fundamental observations important for future studies of bitumen aging.

\section{Compliance with ethical standards}

Conflict of interest The authors declare that they have no conflict of interest.

Open Access This article is distributed under the terms of the Creative Commons Attribution 4.0 International License (http:// creativecommons.org/licenses/by/4.0/), which permits unrestricted use, distribution, and reproduction in any medium, provided you give appropriate credit to the original author(s) and the source, provide a link to the Creative Commons license, and indicate if changes were made. 


\section{References}

1. A. Institute (2001) Construction of HMA Pavements. Manual Series No. 22 (MS-22). Asphalt Institute, Lexington, $\mathrm{KY}$

2. Lesueur D (2009) The colloidal structure of bitumen: consequences on the rheology and on the mechanisms of bitumen modification. Adv Colloid Interface Sci 145(1-2): 42-82

3. Redelius P (2000) Solubility parameters and bitumen. Fuel 79:27-35

4. McKenna AM, Marshall AG, Rodgers RP (2013) Heavy petroleum composition. 4. Asphaltene compositional space. Energy Fuels 27:1257-1267

5. Quddus MA, Sarwar SN, Khan F (1995) The chemical composition of catalytic air blown asphalt. Fuel 74(5):684-689

6. Petersen JC (ed) (2001) A review of the fundamentals of asphalt oxidation. Chemical physiochemical, physical property, and durability relationship, Transportation Research Circular E-C140. Transportation Research Board, Washington, DC

7. Redelius P, Soenen H (2015) Relation between bitumen chemistry and performance. Fuel 140:34-42

8. Qin Q, Schabron J, Boysen R, Farrar M (2014) Field aging effect on chemistry and rheology of asphalt binders and rheological predictions for field aging. Fuel 121:86-94

9. Glover C, Han R, Jin X, Prapaitrakul N, Cui Y, Rose A, Lawrence J, Padigala M, Arambula E, Park E, Martin A (2014) Evaluation of binder aging and its influence in aging of of hot mix asphalt concrete: technical report, Texas Department of Transportation, Austin

10. Marsac P, Pierard N, Porot L, Van den Bergh W, Grenfell J, Mouillet V, Pouget S, Besamusca J, Farcas F, Gabet T, Hugener M (2014) Potential and limits of FTIR methods for reclaimed asphalt characterisation. Mater Struct 47: 1273-1286

11. Soenen H, Lu X, Laukkanen O-V (2016) Oxidation of bitumen: molecular characterization and influence on rheological properties. Rheol Acta 55(4):315-326

12. Liu X, Sjövall P, Soenen H (2017) Structural and chemical analysis of bitumen using time-of-flight secondary ion mass spectrometry (TOF-SIMS). Fuel 199:206-218

13. Corbett L (1969) Composition of asphalt based on generic fractionation, using solvent deasphaltening, elution-adsorption chromatography and densimetric characterization. Anal Chem 41(4):576-579

14. Petersen J, Barbour F, Dorrence S (1974) Catalysis of asphalt oxidation by mineral aggregate surfaces and asphalt components. In: Proceedings Association of Asphalt Paving Technologists. Williamsburg, Virginia

15. Makowska M, Pellinen T, Olmos Martinez P, Laukkanen O (2014) Analythical methodology to determine the composition of filler used in hot-mix asphalt. Case study. Transp Res Rec J Transp Res Board 2445:12-20

16. Nciri N, Song S, Kim N, Cho N (2014) Chemical characterization of gilsonite bitumen. Pet Environ Biotechnol 5(5): 193

17. Makowska M, Pellinen T (2015) Etchable iron content $(\mathrm{FETCH})$ proposed as the missing parameter for the better prediction of asphalt mastic stiffening. Constr Build Mater 93:528-541

18. Kringos N, Khedoe R, Scarpas A, deBondt A (2011) A new asphalt concrete moistue susceptibility test methodology. In: Transportation Research Board 90th Annual Meeting. Washington, DC

19. Manning DG (1995) Synthesis of highway practice 220 waterproofing membranes for concrete bridge decks. National Academy Press, Washington, DC

20. Zhang X, Rao W, Chan SWH, Chan PWH (2009) Iron(III) chloride catalysed direct nucleophilic alfa-substitution of Morita-Baylis-Hillman alcohols with alcohols, arenes, 1,3dicarbonyl compounds and thiols. Org Biomol Chem 7(20):4133-4320

21. SFS-EN 12607-1:2014 Bitumen and bituminous binders. Determination of the resistance to hardening under influence of heat and air. Part 1: RTFOT method. https://sales. sfs.fi/fi/index/tuotteet/SFS/CEN/ID2/1/309123.html.stx. Accessed 1 Feb 2017

22. Jemison HB, Burr BL, Davison RR, Bullin JA, Glover CJ (1992) Application and use of the ATR, FTR-IR method to asphalt aging studies. Fuel Sci Technol Int 10:795-808

23. Isacsson U, Karlsson R (2003) Laboratory studies of diffusion in bitumen. J Mater Sci 23:2835-2844

24. Petersen J, Dorrence S, Nazir M, Plancher H, Barbour F (1981) Oxidation of sulfur compounds in petroleum residues: reactivity-structural relationships. Div Pet Chem Am Chem Soc 26(4):898-906 (Preprints)

25. Plancher H, Dorrence SM, Petersen JC (1977) Identification of chemical types in asphalts strongly adsorbed at the asphalt-aggregate interface and their relative displacement by water. In: Proceeding Association of Asphalt Paving Technologists. San Antonio

26. Cipone C, Davison R, Burr B, Glover C, Bullin J (1991) Evaluation of solvents for extraction of residual asphalt from aggregates. Transp Res Rec 1323:47-52

27. Chen J, Zhou Q, Sun S (2016) Direct chemical characterization of natural wood resins by temperature-resolved and space resolved Fourier transform infrared spectroscopy. J Mol Struct 1115:55-62

28. Nishikawa Y, Nakano T, Noda I (2014) Molecular interaction of polyimide films probed by using soft-pulse dynamic compression ATR time-resolved infrared and double fourier-transform based 2D-IR spectroscopy. Vib Spectrosc 72:79-89

29. Harrick N (1967) Internal reflection spectroscopy. Interscience Publishers, New York

30. IUPAC. Compiled by Alan D. McNaught and A. Wilkinson, Compendium of Chemical Terminology - Gold Book, Royal Society of Chemistry, Wiley, Cambridge, UK, 1997 (Online corrected version 2006-)

31. NIST Mass Spec Data Center (2017) S.E. Stein, director, "Infrared Spectra," in NIST Chemistry WebBook, NIST Standard Reference Database Number 69, Gaithersburg MD, 20899, Linstrom PJ, Mallard WG (eds), National Institute of Standards and Technology

32. Joint FAO/WHO Expert Committee on Food Additives (2006) Combined compendium of food additive specifications, online edition: "Specifications for Flavourings", vol 4. Food and Agriculture Organization of the United Nations, Rome 
33. ThermoFischer Scientific, 139 2016. https://www. thermofisher.com/order/catalog/product/912A0760

34. Pike Technologies, 139 2016. https://www.piketech.com/ files/pdfs/GladiWithOptionsPDS.pdf

35. Bain O, Giguere P (1954) Hydrogen peroxide and its analogues VI. Infrared spectra of H2O2, D2O2 and HDO2. Can J Chem 33:527-545

36. Gianella M, Sigrist M (2012) Chemical analysis of surgical smoke by infrared laser spectroscopy. Appl Phys B 109(3):485-496

37. Jin X, Han R, Cui Y, Glover C (2011) Fast-rate-constantrate oxidation kinetics model for asphalt binders. Ind Eng Chem Res 50:13373-13379

38. Green J, Yu S, Pearson J, Reynolds J (1993) Analysis of sulfur compound types in asphalt, strategic highway research program. National Research Council, Washington, DC

39. Zeng H, Isacsson U (1997) Relationships between bitumen chemistry and low temperature behaviour of asphalt. Constr Build Mater 11(2):83-91

40. Gawel I, Czechowski F, Kosno J (2016) An environmental friendly anti-ageing additive to bitumen. Constr Build Mater 110:42-47

41. Blomberg T, Makowska M, Pellinen T (2016) Laboratory simulation of bitumen aging and rejuvenation to mimic multiple cycles of reuse. Transp Res Procedia 14(Transport Research Arena TRA2016):694-703

42. Braye E, Sehon A, Darwent BB (1955) Thermal decomposition of sulfides. J Am Chem Soc 77(20):5282-5285

43. Plaza S, Gruzinski R (1996) Homogenous and heterogenous thermal decomposition of diphenyl disulphide. Wear 194:212-218

44. Knotnerus J (1972) Bitumen durability-measurement by oxygen absorption. Ind Eng Chem Prod Res Dev 11(4): 411-422
45. Shreve O, Heether M, Knight H, Swern D (1951) Infrared absorption spectra of some hydroxyperoxides, peroxides and related compounds. Anal Chem 23(2):282-285

46. Oswald AA, Wallace TJ (1966) Anionic oxidation of thiols and co-oxidation of thiols with olefins. In: Kharasch N, Meyers CY (eds) The chemistry of organic sulfur compounds, vol 2. Pergamon Press, Great Britain, pp 205-232

47. Bagiyan G, Koroleva I, Soroka N, Ufimstev A (2003) Oxidation of thiol compounds by molecular oxygen in aqueous solutions. Russ Chem Bull Int Ed 52(5):1135-1141

48. Lesueur D, Petit J, Ritter H-J (2013) The mechanisms of hydrated lime modification of asphalt mixtures: a state-ofthe-art review. Road Mater Pavement Des 14(1):1-16

49. Dickinson E (1974) The Constitution and quality of paving grade asphalts produced by air blowing distillation residues of Kuwait and "Light" Arabian" crude oil. Proceedings of the Association of Asphalt Paving Technologists, Technical Sections 43:132-161

50. Bonon A, Mandelli D, Kholdeeva O, Barmatova M, Kozlov Y, Shul'pin G (2009) Oxidation of alkanes and olefins with hydrogen peroxide in acetonitrille solution catalyzed by a mesoporous titanium silicate Ti-MM-2. Appl Catal A Gen 365(1):96-104

51. March J (1992) Advanced organic chemistry. Wiley-Interscience, New Jersey

52. Herrington P (1995) Thermal decomposition of asphalt sulfoxides. Fuel 74(8):1232-1235

53. Laibinis P, Whitesides G (1992) Self-assembled monolayers of n-alkanethiolates on copper are barrier films that protect the metal against oxidation by air. J Am Chem Soc 114(23):9022-9028 